\title{
Research Paper \\ Promoting Mental Health in Workplaces of Iran; Reviewing Present Status and Future Approaches
}

\author{
Behzad Damari ${ }^{1}$ (1) Seyed Hossein Almadani², Ahmad Hajebi ${ }^{3},{ }^{*}$ Narges Salehi Shahrabi ${ }^{4}$ (i)
}

1. MD, MPH, MFPH, Community Medicine Specialist, Associated Professor of Tehran University of Medical Sciences, Health \& Governance Department, Brain \& Spinal Cord Injuries center of Neuroscience Institution, Tehran University of Medical Sciences, Tehran, Iran.

2. PhD. Student in Psychology, Deputy General Manager in the Ministry of Cooperatives, Labor, and Social Welfare of Iran, Tehran, Iran.

3. Professor, Risky Behaviors (ReCARB), Research Center for Addiction, Psychiatric Department, Iran University of Medical Sciences, Tehran, Iran.

4. PhD. in Public Administration, Department of Research Assistant at Health \& Governance, Brain \& Spinal Cord Injuries Center of Neuroscience Institution, Tehran University of Medical Sciences, Tehran, Iran.

\begin{tabular}{|c|c|}
\hline $\begin{array}{l}\text { Use your device to scan } \\
\text { and read the article online }\end{array}$ & eftetion Damari B, Almadani SH, Hajebi A, Salehi Shahrabi N. [Promoting Mental Health in Workplaces of Iran; Reviewing \\
\hline 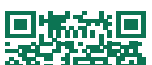 & $\begin{array}{l}\text { Present Status and Future Approaches (Persian)]. Iranian Journal of Psychiatry and Clinical Psychology. 2019; 25(2):122-135. } \\
\text { http://dx.doi.org/10.32598/ijpcp.25.2.122 }\end{array}$ \\
\hline aristis & 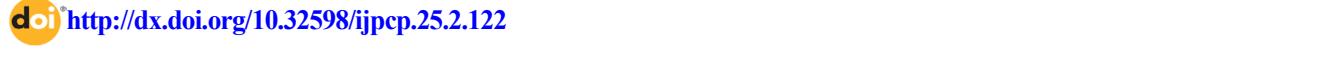 \\
\hline
\end{tabular}

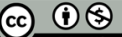

Received: 06 Sep 2018 Accepted: 24 Feb 2019 Available Online: $01 \mathrm{Jul} 2019$

Key words:

Mental health, Mental disorder, Workplace, National policy

\begin{abstract}
A B S T R A C T
Objectives The purpose of this study was to survey the mental and social health status in Iranian workplaces and recommend promoting approaches.

Methods This research has a qualitative-dominant mixed-methods design. The study data were collected through review of documents and resources, interviews, and group discussions. The results were classified in three separate areas of the current situation, future direction, and requirements of implementation.

Results Analysis of data revealed that mental health plans for workplaces were autonomous and voluntarily not pre-planned or based on national policy. Also, the evaluation was not performed before and after the intervention. Recommended approaches to promote mental and social health are administrating promotional interventions, compulsory interventions, and facilitative interventions.

Conclusion The recommended approaches in this study should be approved by the coordination council for health services of the insured people and gradually be implemented in the framework of a national policy for promoting social and mental health throughout the country and first from one province as a pilot study.
\end{abstract}

\section{Extended Abstract}

\section{Introduction}

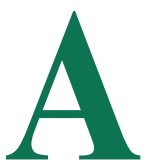

ccording to the World Health Organization definition, mental health is not just lack of mental disorders but comprises subjective well-being, perceived self-efficacy, autonomy, competence, intergenerational dependence and self-actualization of one's intellectual and emotional potential [1]. Approximately 919 million people are suffering from psychiatric disorders around the world [2]. According to the latest survey, $33 \%$ of the workforce in Iran suffer from mental disorders. Therefore, reducing this level of mental disorders requires a national plan.

In addition to the personal, biological, genetic, and the environment (in which one grows up), the mental health in workplaces depends on satisfaction with the job specifications, cultural environment, the income, communication with colleagues, and the irrational discrimination $[7,8,9]$.

\section{* Corresponding Author:}

Narges Salehi Shahrabi, PhD. Student

Address: Department of Research assistant at Health \& Governance, Brain \& Spinal Cord Injuries Center of Neuroscience institution, Tehran University of Medical Sciences, Tehran, Iran.

Tel: +98 (21) 88983549

E-mail: nargesalehi@gmail.com 
Based on the statistic, more than $80 \%$ of people are accessible in the workplaces. Therefore, health programs in workplaces are one of the key health promotion interventions. Mental health promotion can be part of human resource management policies, and treatment of mental health problems in their early stages of diagnosis is critical [5].

Improving mental disorders in workplaces and labor communities need national policy plans and the agreement of key officials, including representatives of employers and workers, and suppliers of services and resources. The purpose of this study is to survey the mental and social health status in Iranian workplaces and to recommend promoting approaches.

\section{Method}

A mixed method (qualitative-quantitative) was used in this study, whereby the dominant part was qualitative. The study data were collected through review of documents, interviews, and group discussions. The results were classified in three separate areas of the current situation, future direction, and requirements of implementation.

The qualitative section includes stakeholder analysis, interviews, group discussion, organizational status analysis, and document review. A stakeholder analysis was conducted by the commitment-impact matrix to form a leading technical committee. The level of experience and expertise of the legal entities was considered to select the member of the leading committee. The purposeful sampling was done for interviews and choosing members of the focused group. A public health specialist organized and held the interviews. Questions were initially emailed to individuals, and then, face-to-face interviews were performed.

The obtained data were analyzed by thematic analysis method, and the results were presented in three separate sections: 1. Understanding the current status including the review of the existing data, evaluating previous interventions and upper-hand documents; 2. Future directions including prospects, strategic goals; and 3. Interventions and implementing obligations including the required resources, monitoring and evaluation indicators, motivation patterns, implementation structure, the capability of executive staffs and manuals prepared.

Furthermore, the interventions were categorized into three groups; promotional, facilitative, and compulsory interventions. Then, the leading committee revised and finalized the presented results.

\section{Results}

The data collected from questionnaires shows the average prevalence of mental health in workplaces was 34.5\% in Iran in 2016. The details of mental health dimensions shown in Table 1.

Table 1. Statistical indexes of mental health in workplaces

\begin{tabular}{|c|c|c|}
\hline Row & The Problems of Workplaces & Mean \\
\hline 1 & Lack of health and safety in the workplace & 23.84 \\
\hline 2 & Failure to respect human dignity & 7.91 \\
\hline 3 & The unhealthy mental atmosphere in the workplace & 8.19 \\
\hline 4 & Inappropriate management & 5.06 \\
\hline 5 & Job insecurity & 6.83 \\
\hline 6 & Lack of supportive laws & 4.19 \\
\hline 7 & Stress due to workload & 7.40 \\
\hline 8 & Occupational discrimination and injustice & 6.72 \\
\hline 9 & Lack of career development & 6.02 \\
\hline 10 & Lack of supportive infrastructure & 11.44 \\
\hline 11 & Salaries and benefits & 2.59 \\
\hline 12 & Family problems & 4.73 \\
\hline 13 & Financial worries & 8.24 \\
\hline 14 & Mental problems & 1.09 \\
\hline 15 & The workplace problems (total score) & 103.67 \\
\hline
\end{tabular}


Table 2. Achieved results of the Ministry of Cooperatives, Labor, and Social Welfare of Iran

\begin{tabular}{cc}
\hline Type of Intervention & \multicolumn{1}{c}{ Description } \\
\hline Promotional & $\begin{array}{l}\text { Providing a tutorial package about mental health specific for employees and employers, designing and institution- } \\
\text { alizing a mental health promotion training course in workplaces, designing and presenting mental health educa- } \\
\text { tion package for in-person training for workplaces (less than } 50 \text { employees- between } 50 \text { to } 500 \text { employees- over } \\
500 \text { employees). }\end{array}$ \\
& $\begin{array}{l}\text { Ranking the workplaces and employers in terms of compliance with the laws and regulations of the workplaces } \\
\text { to improve mental and social status, implementing standards of labor inspectors to supervise the obligations of a } \\
\text { suitable workplace to improve mental and social status, health insurance coverage for mental disorders and provi- } \\
\text { sions of services for acute mental problems due to trauma }\end{array}$ \\
& $\begin{array}{l}\text { Expansion of phone counseling services, establishing staff-help centers in all workplaces from } 50 \text { to } 500 \text { staff, } \\
\text { Screening preparation, Brief Intervention, and Referral to Treatment (SBIRT), establishing Employee Assistance } \\
\text { Coordinates (EACs) to find resources in the community for getting help, the employer shows a contract that a } \\
\text { specialized clinic or center takes the responsibility of care and treatment of mental disorders in the workplace } \\
\text { when referred from the workplace. }\end{array}$ \\
\hline
\end{tabular}

PSYCHIATRY AND CUNICAL PSYCHOLOGY

According to the achieved results, the Ministry of Cooperatives, Labor, and Social Welfare of Iran with the assistance of inter-sectoral cooperation and participation of the union of employees and employers plans to reduce mental disorders down to $25 \%$ of mental diseases in the starting year, and increase in the level of social capital and happiness among labor communities by 2020 . Details of this report shown in Table 2.

\section{Ethical Considerations}

\section{Compliance with ethical guidelines}

All ethical principles were considered in this research. The participants and interviewees were informed about the purpose of the study and they were also assured about the confidentiality of their data. Furthermore, they were free to leave the study whenever they want.

\section{Funding}

This study was conducted and financially supported by the Ministry of Cooperatives, Labor, and Social Welfare of Iran.

\section{Authors contributions}

Conceptualization: All authors; Methodology: Behzad Damari; Investigation: Narges Salehi Shahrabi, Seyed Hossein Hajebi; Writing-original draft: Narges Salehi Shahrabi, Behzad Damari; Writing-review and editing: Seyed Hossein Almadani, Behzad Damari; Funding acquisition: Seyed Hossein Hajebi, Seyed Hossein Almadani; Resources: Narges Salehi Shahrabi, Behzad Damari; Supervision: Behzad Damari.

\section{Conflicts of interest}

The authors declared no conflict of interest.

\section{Acknowledgements}

This study was proposed by the Development, Prevention, and Treatment center of the sWelfare Organization to be used by Department of Social Affairs at the Minister of Cooperatives, Labor and Social Welfare in Iran. The authors would like to thank the relevant authorities especially Dr. Gholamreza Bostanmanesh, and all particpants for their valuable cooperation 


\title{
رويكردهاى ارتقاى سلامت روان در محيطهاى كارى كشور ايران، مرورى بر وضعيت موجود و ارائه راهكار رايي براى آينده
}

\author{
بهزاد دمارى' ن. سيد حسين المدنى"، احمد حاجبى" "نركس صالحى شهرابى"

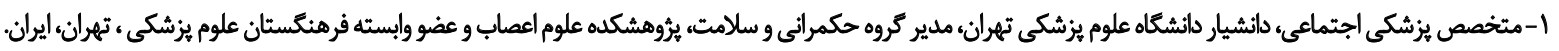

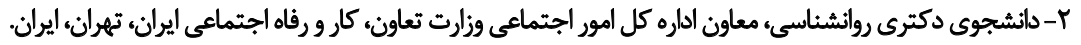

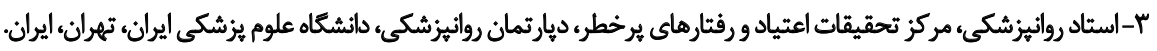

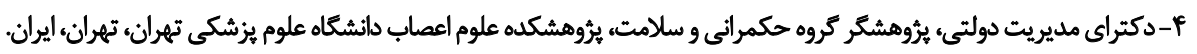

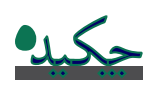

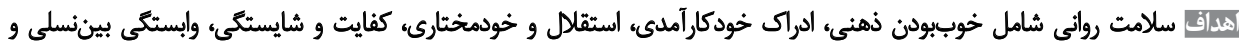

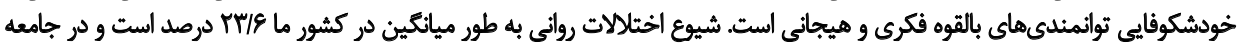

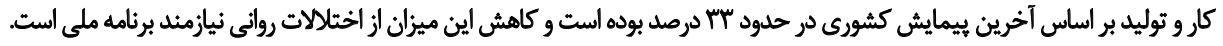

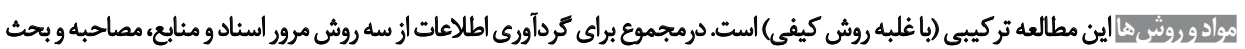

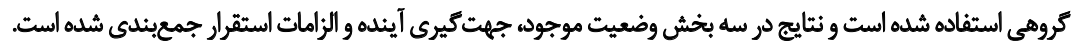

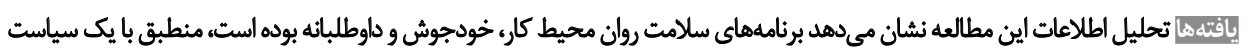

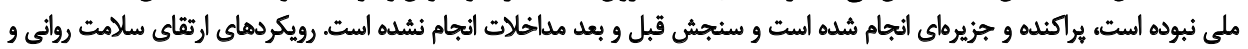

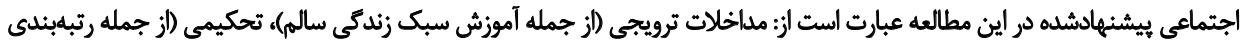

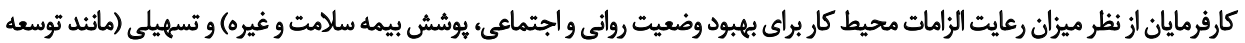

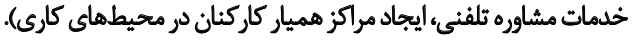

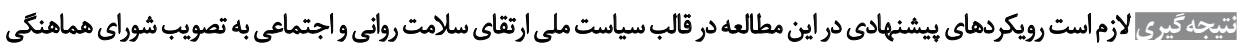

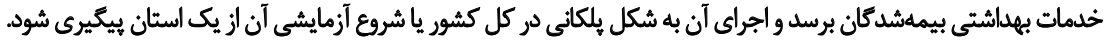

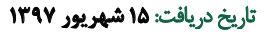

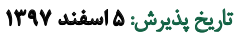

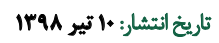

كليدوارهها:

ارتثاى سلامت روان، محيطهاى كارى، كشور جمهورى اسلامى ايران، سياست ملى الغاني

و خود شكوفايى توانمندى هاى بالقوه فكرى و هيجانى مى مشود [T].

Laleo طبق آمار متأسفائه حدود 919 ميليون نفر در سراسر

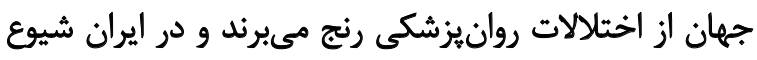

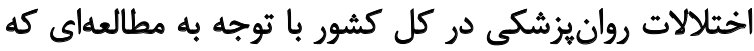

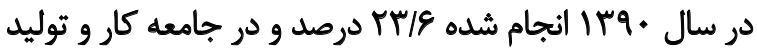

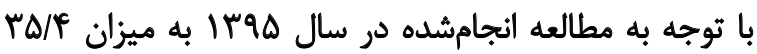

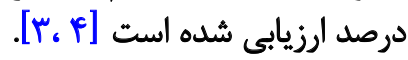
با توجه به ارتباط نزديك سلامت روان با بهداشت عمومى و عوامل

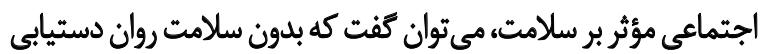

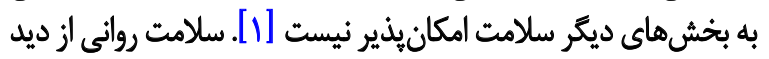

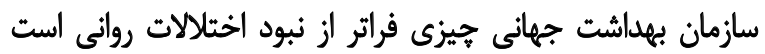

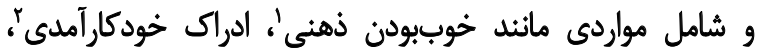

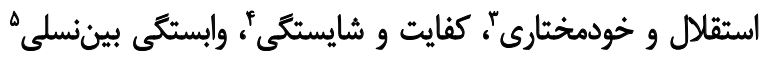

بر اساس تزارش سازمان جهانى بهداشت، بيشتر اختلالات

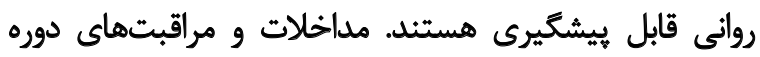

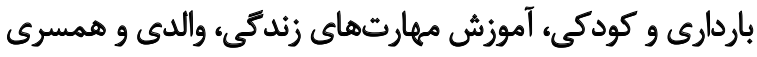

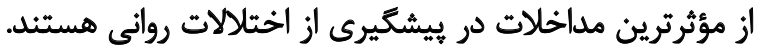
1. Subjective well-being
2. Perceived self-efficacy
3. Autonomy
4. Competence
5. Intergenerational dependence

6. Self-actualization of one's intellectual and emotional potential 


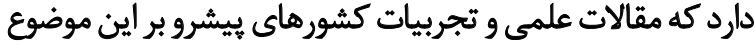

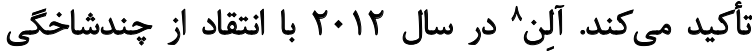

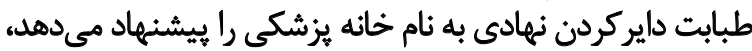

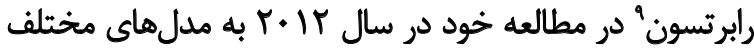

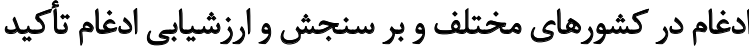

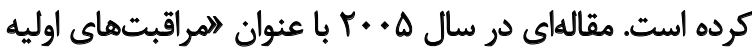

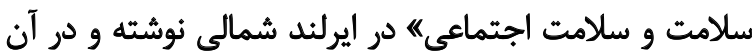

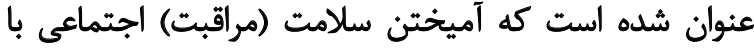

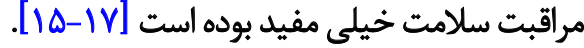

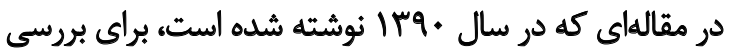

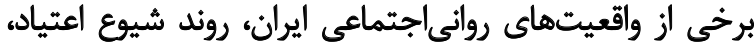

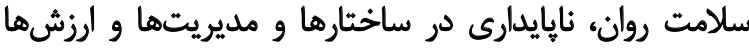

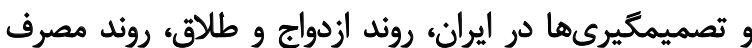

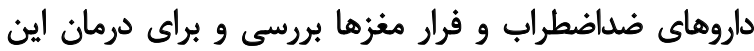

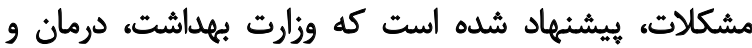

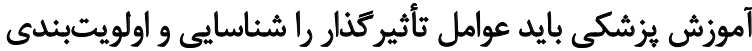

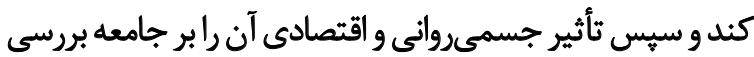

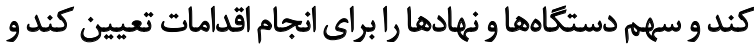

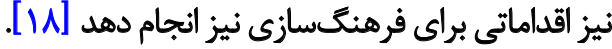

روانيزشكى مبتنى بر جامعه مي تواند جايكزين نظام شبكه

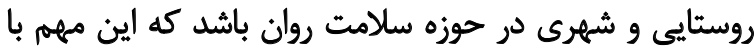

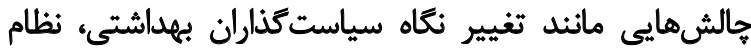

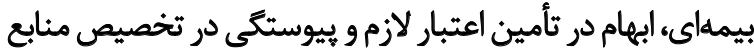

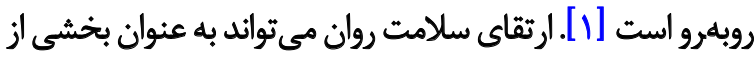

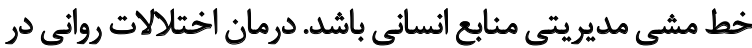

اولين مراحل شناخت بسيار باهميت است [111].

مداخلات بيشنهادى براى تأمين محيط امن روانى در محيط

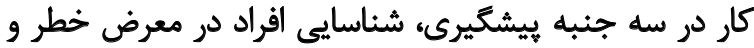

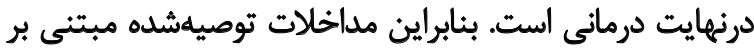

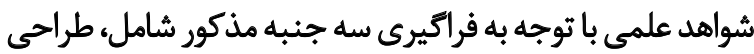

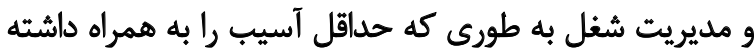

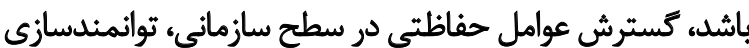

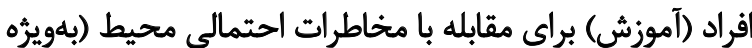

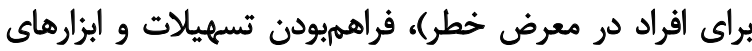

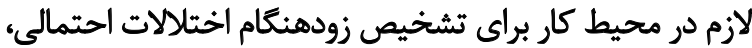

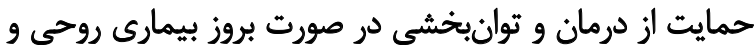

$$
\text { روانى و غيره است. }
$$

در ايران مطالعات متعددى درباره استرسهاى شغلى و ارتباط إنباط

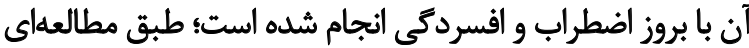

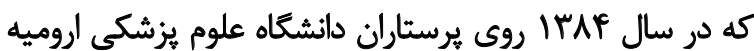

8. Allen

9. Robertson
رويكردهاى مراقبت از بيماران روانى و آموزش خانوادههايي كه

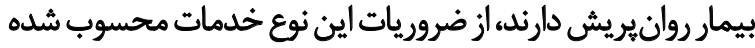

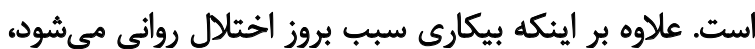

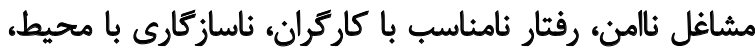

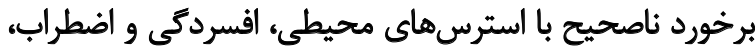

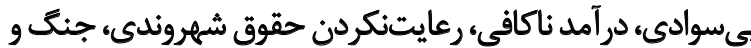

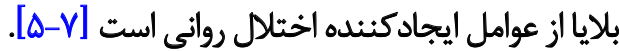

عوامل متعددى علاوه بر مشخصههاى فردىزيستى، رُنتيكى في ئي

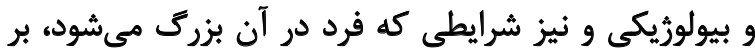

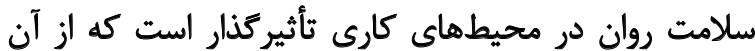

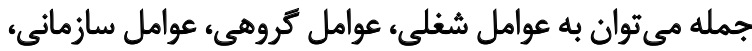

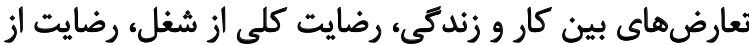

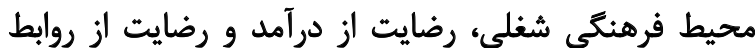

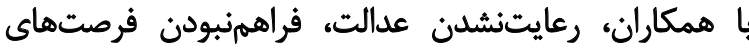

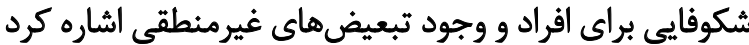

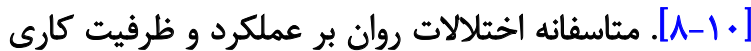

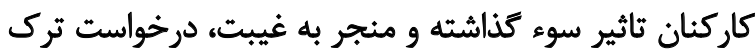

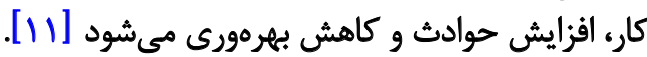
طبق آمار مى توان به • ^مرصد مردم از طريق محيطهاي كارى

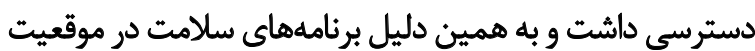

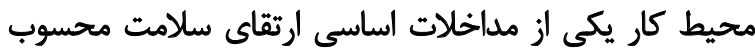

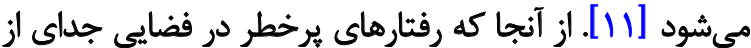

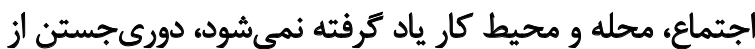

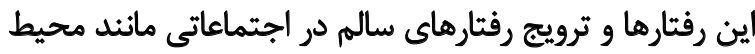

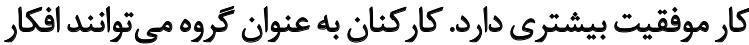

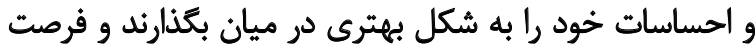

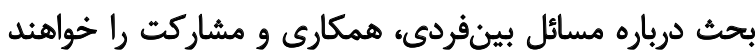

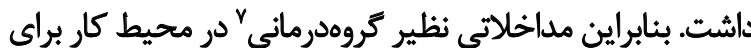

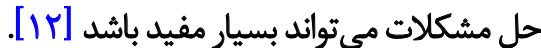
يكى از راهكارهاى ارائه عادلانه خدمات سلامت روان، ادغام

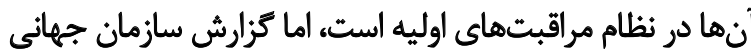

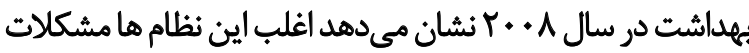

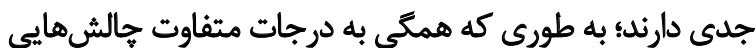

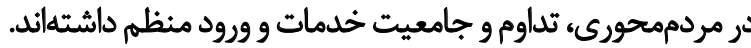

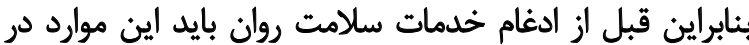

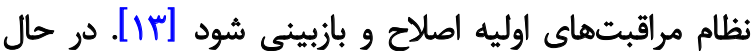

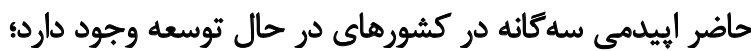

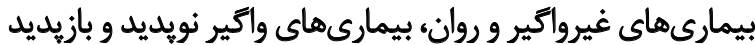

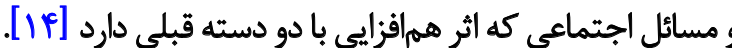
بنابراين مي توان نتيجه كرفت ضرورتى براي ادغام خدمات

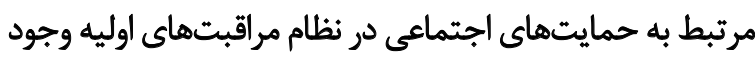

7. Group therapy 
جدول ا. اولويتها براي انتخاب اعضاى كميته راهبرى فنى

\begin{tabular}{|c|c|}
\hline سازمان & حوزه \\
\hline 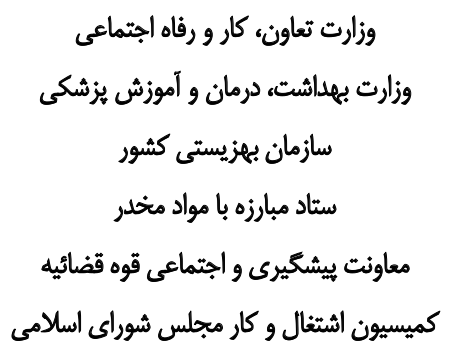 & هديران، سياست كذاران، قانون كذاران و ناظلان \\
\hline 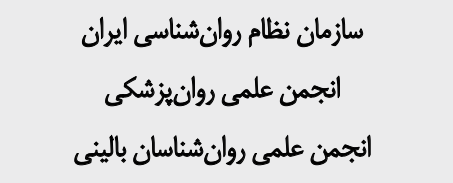 & حوزه اراثه كنثدكان خدمات \\
\hline خانه كاركر و انجمن اسلاي كارفرمايعيى كامي & 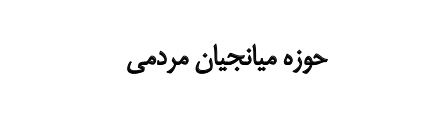 \\
\hline 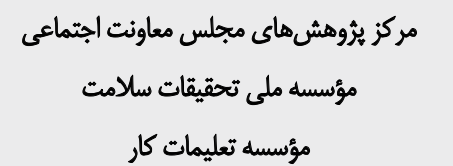 & حوزه هحققان \\
\hline
\end{tabular}

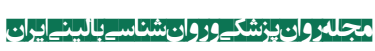

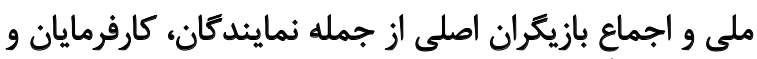

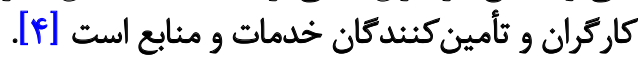

وُش

اين مطالعه از نوع تركيبى (كمى كيفى) با غلبه بخش كيفى نحئ

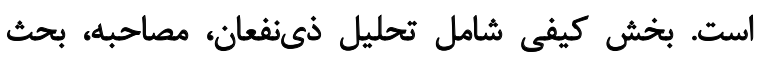

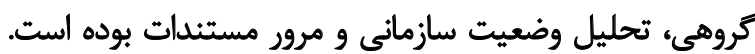

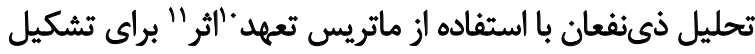

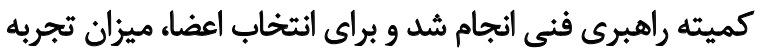

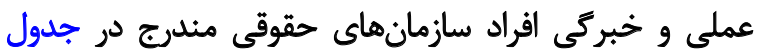

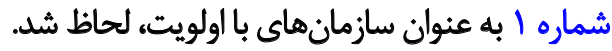

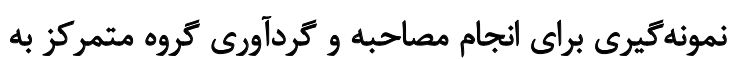

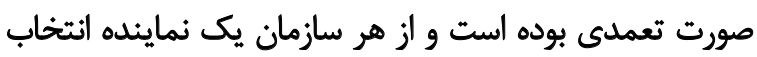

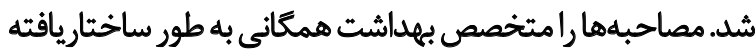

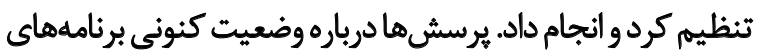

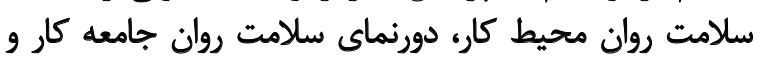

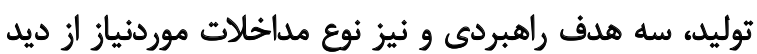
مصاحبهشوندكان بوده است.

10. Commitment

11. Impact
انجام شده است بين استرس شغلى و افسردكى و اضطراب ارتباط

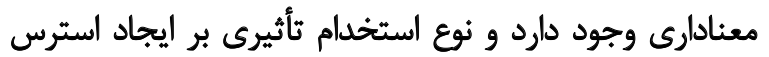

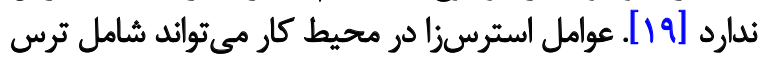

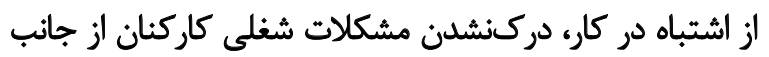

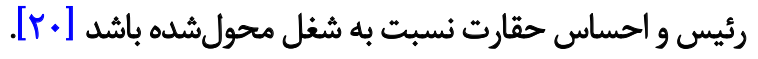
مطالعه ديخرى كه روى كاركنان بيمارستان دانشعاه علوم

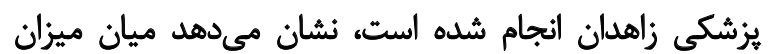

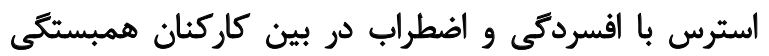

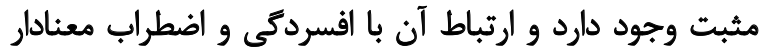

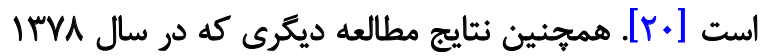

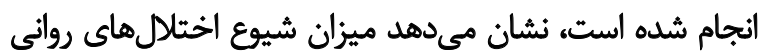

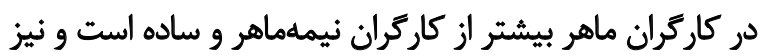

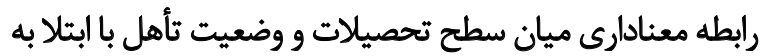

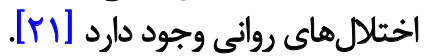

تفاوت اصلى مطالعه حاضر با مطالعات قبلى در اين است كه

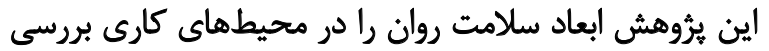

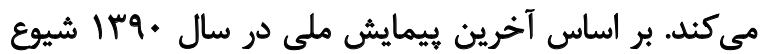

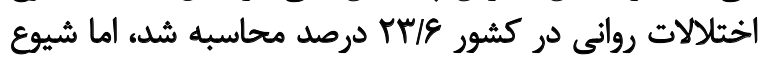

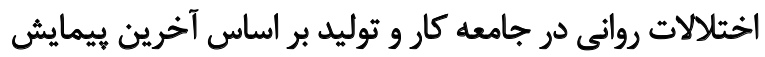

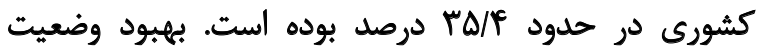
اختلالات روانى در جامعه كار و توليد نيازمند تدوين سياست درد 
توسعه، سند ملى ييشكيرى و كنترل بيمارى هاي غيرواكير، برنامه

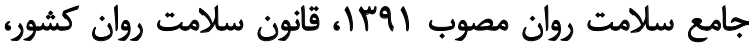

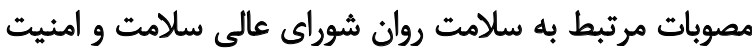

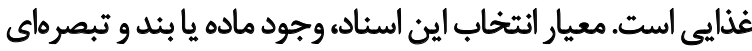

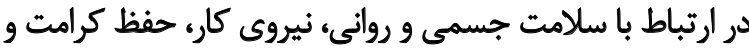

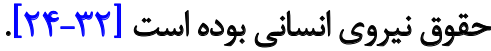

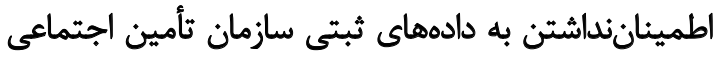

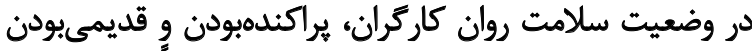

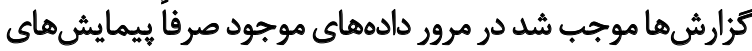

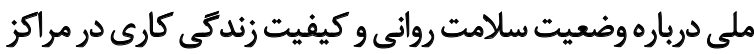

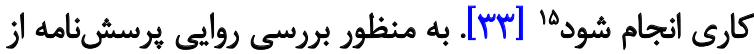

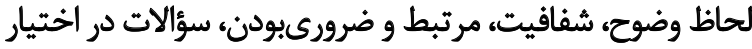

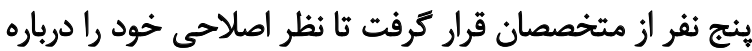

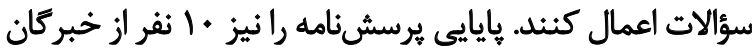
از روش آزمونباز آزمون در فاصله زمانى با هفتهاي انجام دادند. مداخلات نيز در سه تم فرعى ترويجى، (مداخلات آموزش و

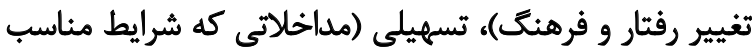

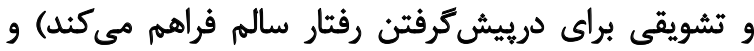
تحكيمى (مداخلاتى كه به حكمي قانو

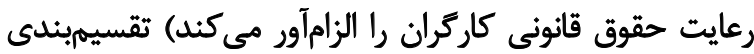

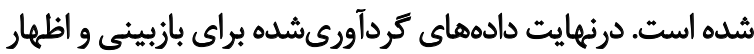

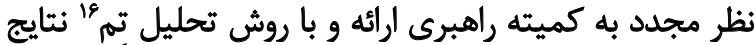

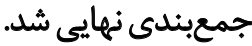

ياقتهنها

بر اساس سؤالات مصاحبه، يافتهها در جهار بخش زير

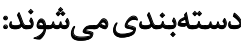

بخش اول:شناخت وضعيث موجود سلامت روان دو جامعه كارو توليد

اطلاعات تردآورى و تحليلشده از مطالعه كمى با استفاده از

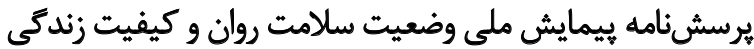

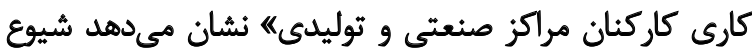

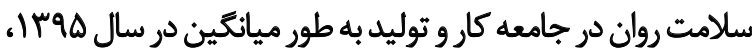

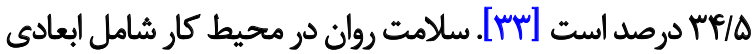

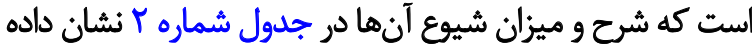

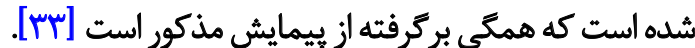

مرور اسناد بالادستى نشان مى دهد به ميزان درخور توجهى در

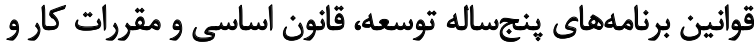
غيره به سلامت سرمايه انسانى در محيط كار توجه شاند شده است: در

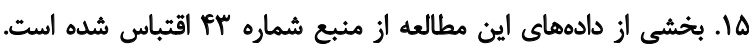

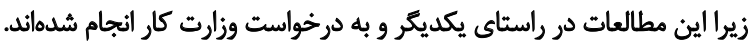
16. Theme

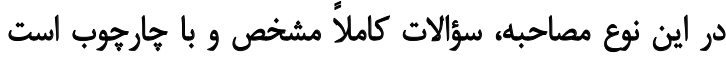

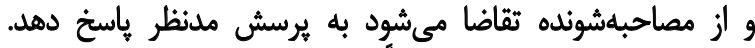

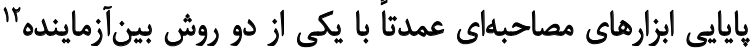

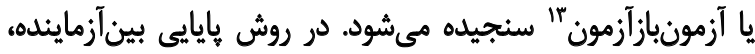

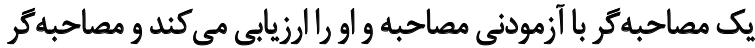

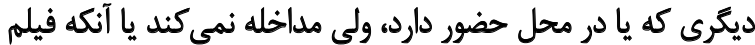

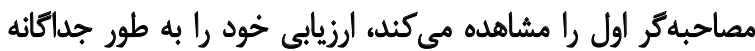

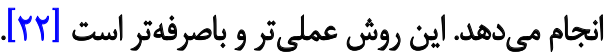
در روش آزمونبازآزمون، دو مصاحبه كر مستقل در فواصل زمانى

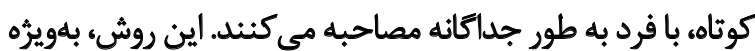

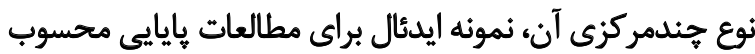

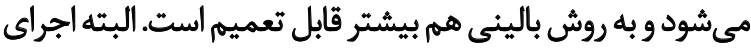

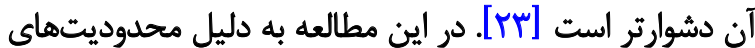
دسترسى به مصاحبهشوندكان از إيايايى اول استفاده شد.

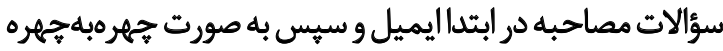

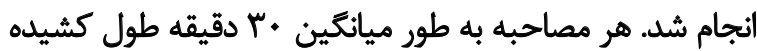

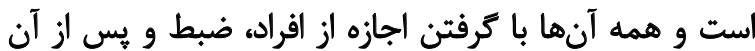

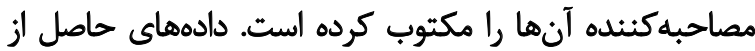

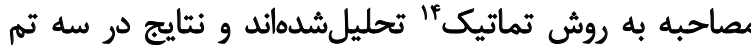

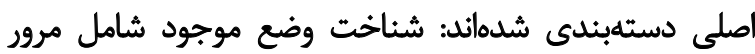

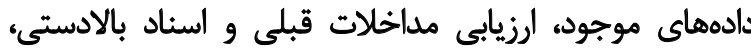

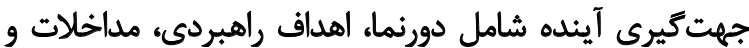

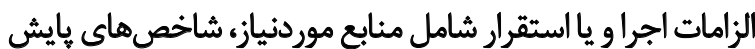

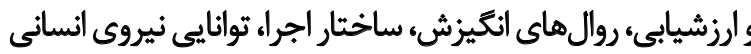

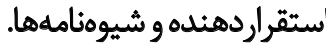

مرور اسناد بالادستى به منظور يافتن اينكه آيا حمايتهاي

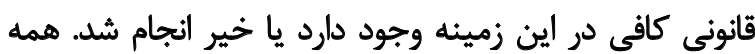

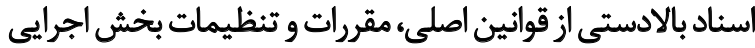

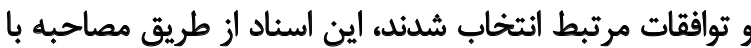

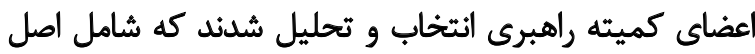

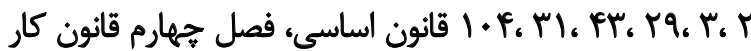

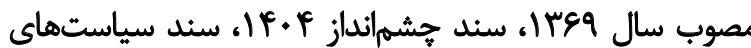

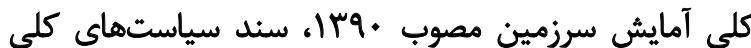

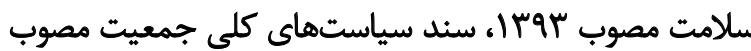

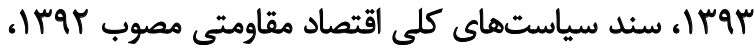

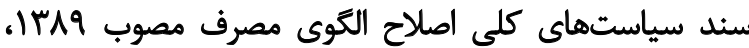

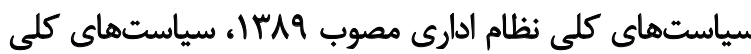

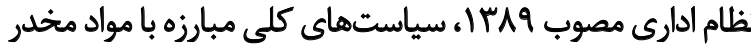

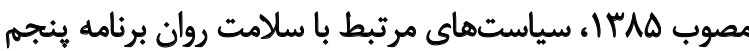

\section{Inter-rater}

13. Test-retest

14. Content Analysis 
جدول r. شاخصهاى آمارى مربوط به ابعاد سلامت روان در محيط (צY)

\begin{tabular}{|c|c|c|}
\hline مياتكين & مشكلات محيط كار & رديف \\
\hline rr/Ar & فقدان بهداشت و ايمثى محيط كار & 1 \\
\hline V/al & رعايتششن جايكاه وكرامت أسانى & r \\
\hline N/9 & جو روانى نامساعد در محيط كار & $r$ \\
\hline$\Delta / .9$ & مديريت نامناسب & p \\
\hline glar & 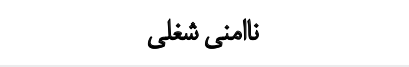 & $\Delta$ \\
\hline$r / 19$ & نبود قوانين حمايتى لازم & $\varepsilon$ \\
\hline$V / F$ & استرس ناشى از حجم كار & $\gamma$ \\
\hline$s / N$ & وجود تبعيض شغلى و بى عدالتى & $\wedge$ \\
\hline 91.4 & نبود امكان رشد و ييشرفت & 9 \\
\hline $11 / 49$ & نبود تسهيلات حمايتى & 1. \\
\hline$r / \Delta q$ & حقوق و مزايا & 11 \\
\hline$F / M$ & مشكلات خانوادكى & ir \\
\hline NTY & 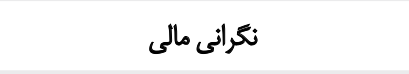 & r \\
\hline $1 / \cdot 9$ & مشكلات رواثى & if \\
\hline $1 . r / 9 V$ & مشكلات محيط كارى (نمره كل مقياس) & 10 \\
\hline
\end{tabular}

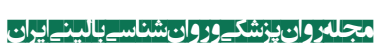

در قانون برنامه هساله ششم توسعه، بر حمايت و يشتيبانى و و

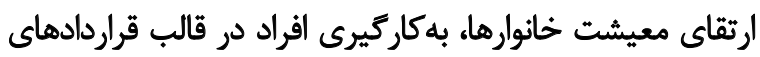

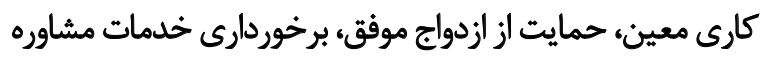

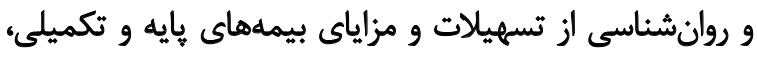

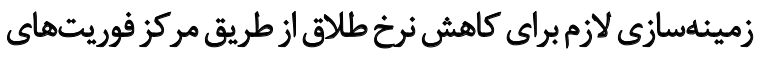

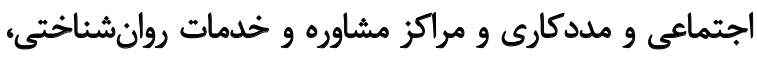

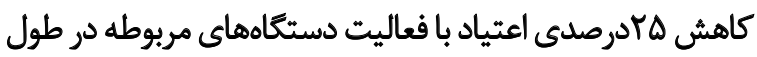

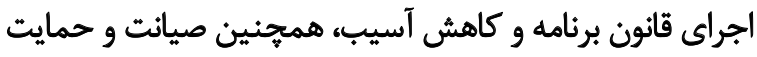

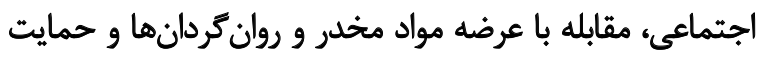

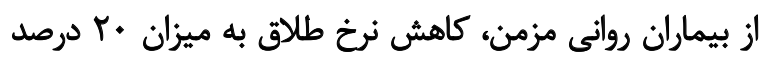

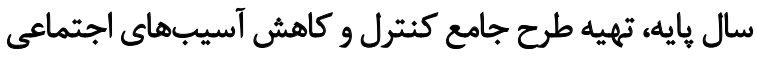

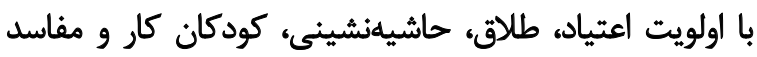

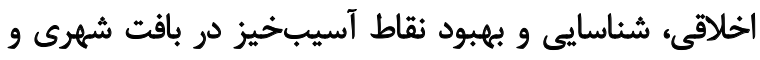

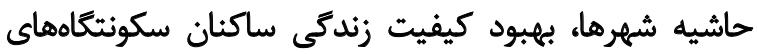

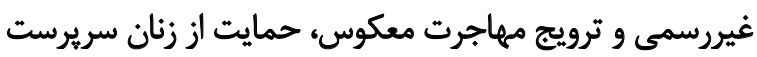
خانوار و مواردى از اين قبيل تأكيد شده است

اطلاعات حاصل از مصاحبهها درباره آسيبهاي موجود مواردائ

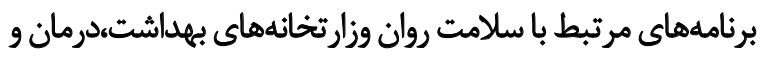

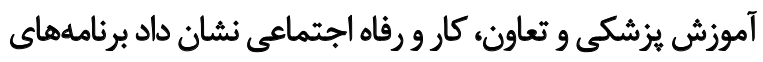

الصل r قانون اساسى، بر ايجاد محيط مساعد براي رشد فضايل

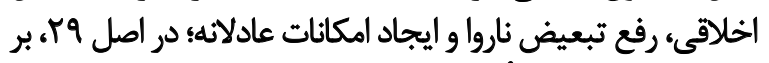

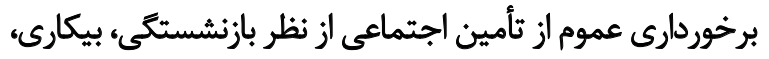

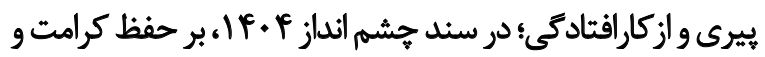

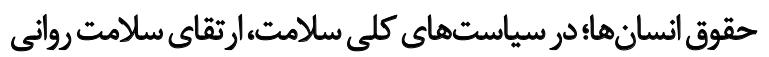

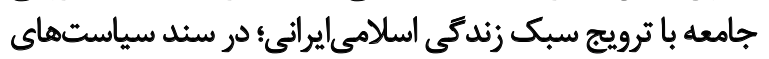

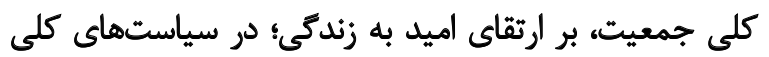

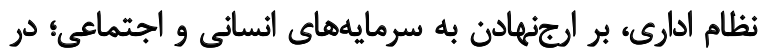

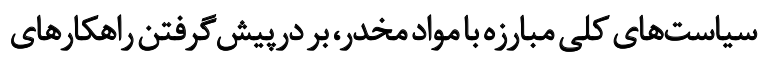

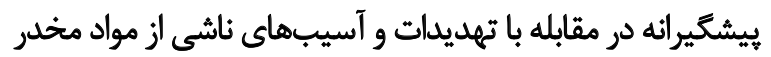

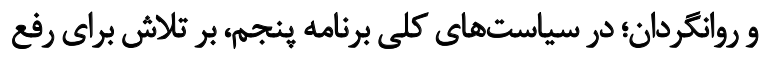

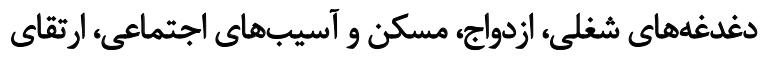

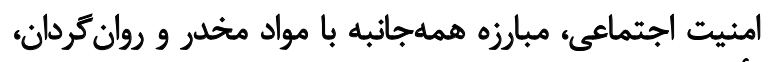

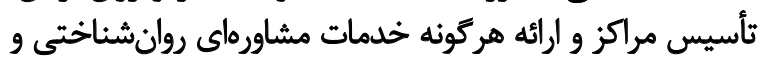

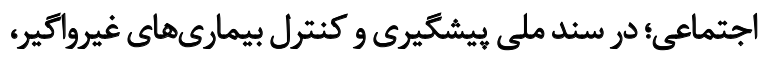

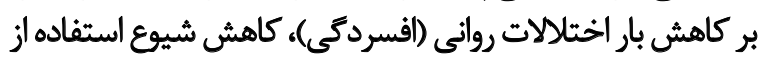

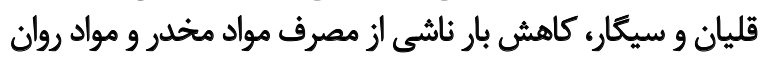

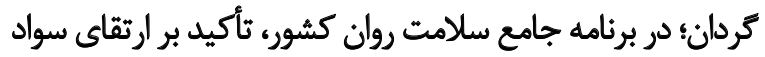

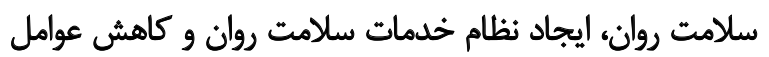

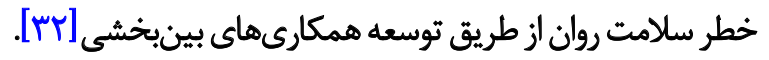


تسهيلى نيز به منظور تسهيل در اجراي برنامههاي بيشنهادى ارائه مىشود. جزئيات اين مداخلات در جدول شماره بـ آمده است.

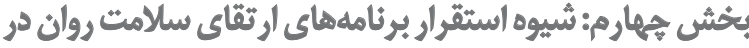
جامعله كار و وتوليد

بر اساس اطلاعات جمعآورىشده و تحليل مباحث كميته

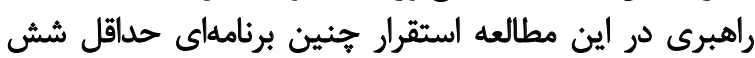

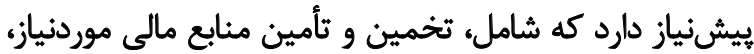

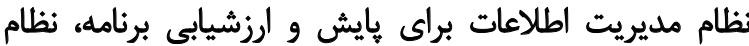

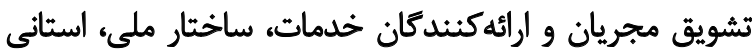

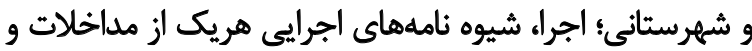
توانمندسازى نيروى انسانى است

نظر اكثريت خبر گان بر اين بوده است كه اولين قدم براى

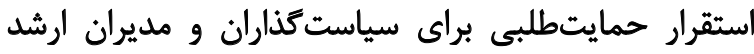

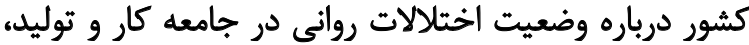

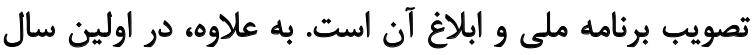

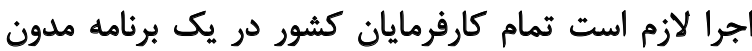

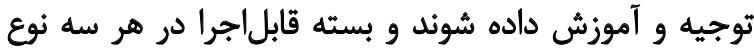

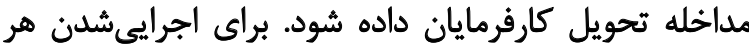

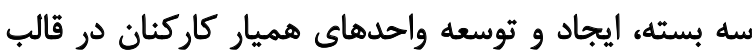

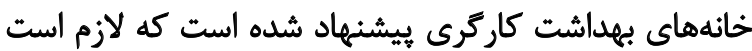

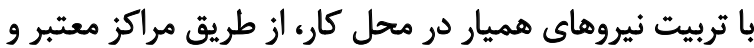

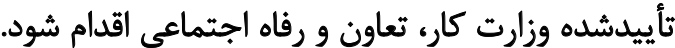
مشخصكردن تكاليف بينبخشى از عوامل بسترساز است

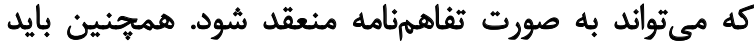

سلامت روان محيط كار خودجوش، قائم به كارفرما و داوطلبانه

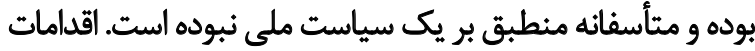

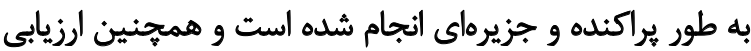
قبل و بعد مداخلات انجام نشده است.

بخش دوم: دورنماى سلامت روان در جامعه كار و توليد

بر اساس نظرات جمعآورىشده، دورنماى سلامت روان

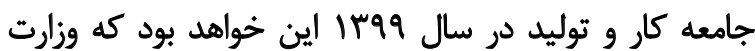

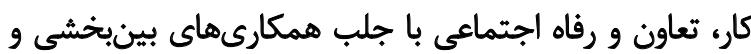

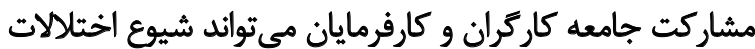

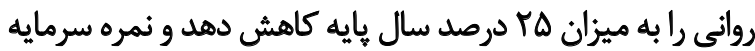

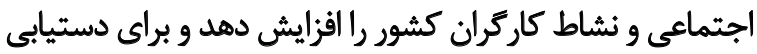

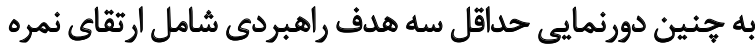

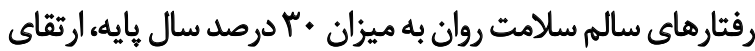

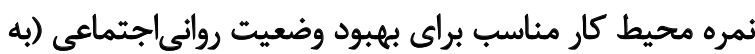

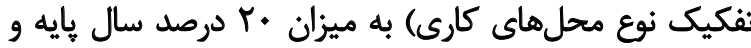

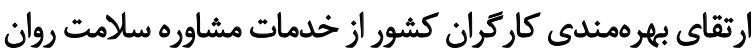

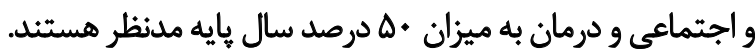
بخش سوم: مداخلات ارتثاى سلامت روان در جامعه كار و توليد مداخلات بيشنهادى خبركان با استفاده از تحليل تم در سه

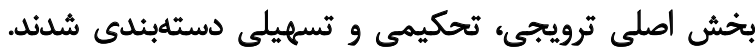

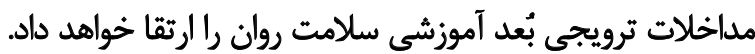

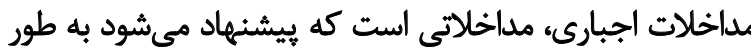

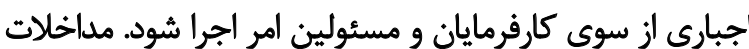

جدول r. شرح مداخلات بيشنهادى خبركان با استفاده از تحليل تم هاى اصلى

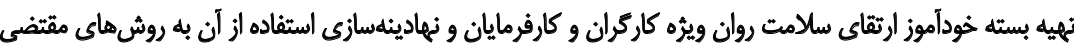

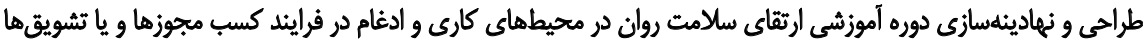

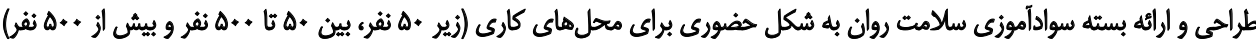

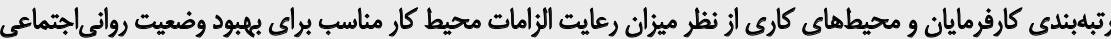

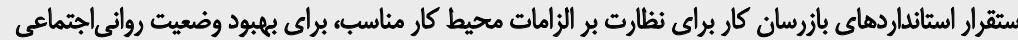

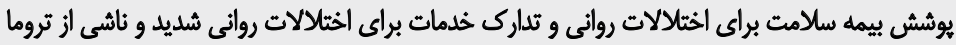


جدول P. زمانيندى براى اجراى سند ملى ارتقاى سلامت روان كاركران

\begin{tabular}{|c|c|}
\hline فعاليت & دوره زماني \\
\hline 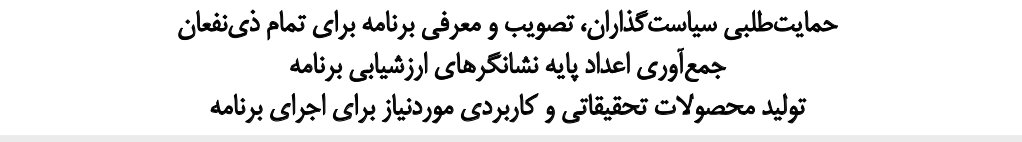 & ازو اولين برال اوله هاجرال هاله \\
\hline 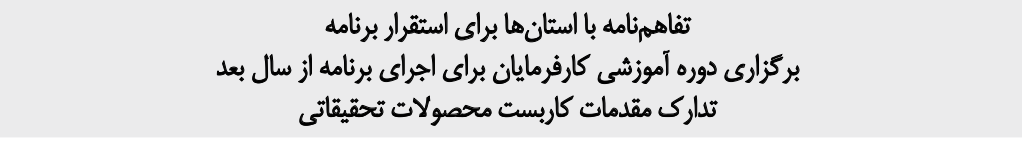 & در سال اول اجرا \\
\hline اولين سال تدارى خدمات ارتقاى سلامت روان، بايش و رتبهبندى و تشويق كارفرمايان و تشكلهاى كاركرى & 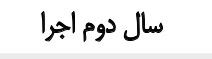 \\
\hline دومين سال تدارى خدمات ارتقاى سلامت روان، بايش و رتبهبندى و تشويق كارفرمايان و تشكل هاى كاركرى & 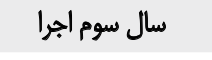 \\
\hline سومين سال تدارى خدمات ارتقاى سلامت روان، بايش و رتبهبندى و تشويق كارفرمايان و تشكلهاى كاركرى & سال جهارم اجرا \\
\hline ارزشيابى ملى برنامه ارتقاى سلامت كاركران و تلدوين كزارش و راه آينده ثا ه سال بعلى & از اولين برنامه هساله \\
\hline
\end{tabular}

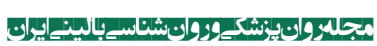

تحكيمى (از جمله رتبهبندى كارفرمايان از نظر ميزان رعايت

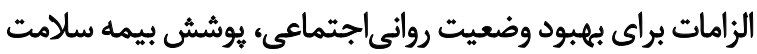

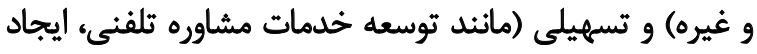

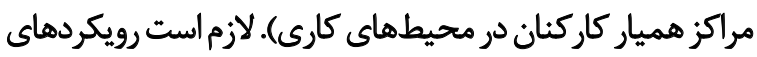

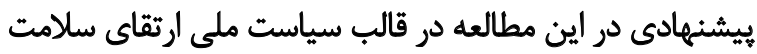

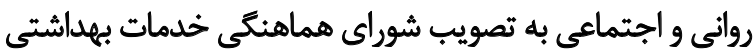

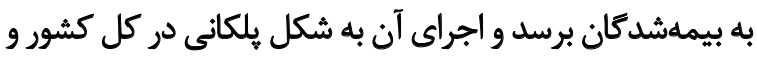

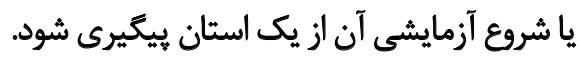

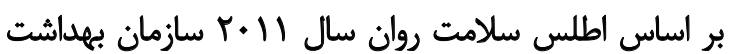

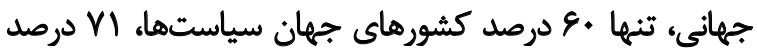

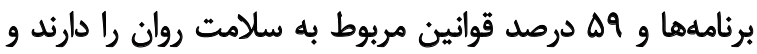

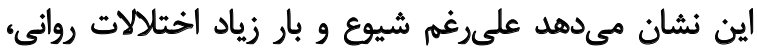

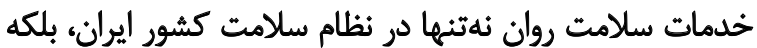

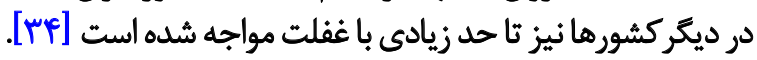

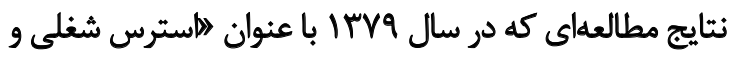

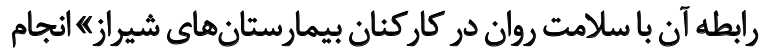

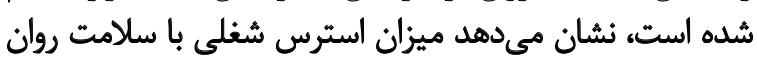
در كاركنان ادارى و درمانى رابطه دارد و حتى حتى كاركني

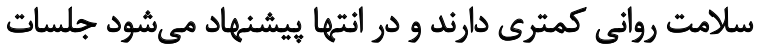

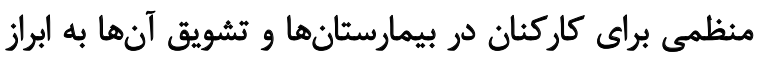
مشكلات موجود در محيط كار تشكيل شود.

همجنين بررسىهايى به منظور سببشناسى استرس شغلى إسى

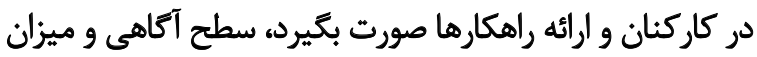

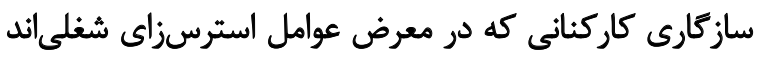

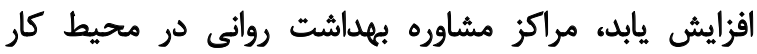

الولويتهاى تحقيقاتى در اين حوزه تعيين شود و. بودجه لازم

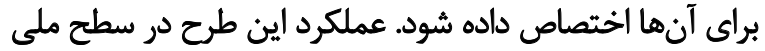

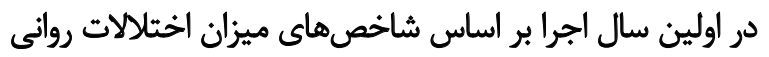

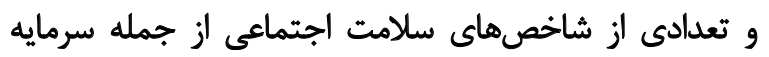

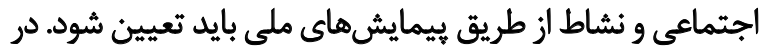

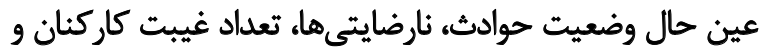

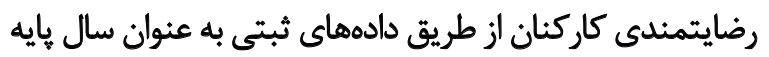

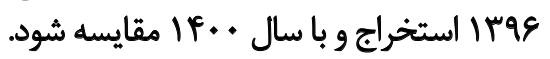

بايد رديف بودجه مشخصى براى تمام يرورزههاى ارتقاى

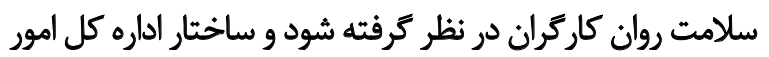

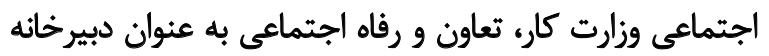

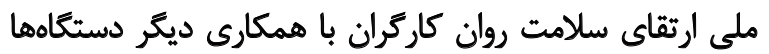

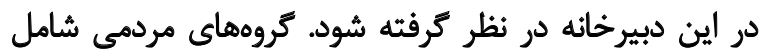

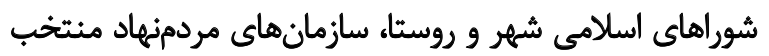

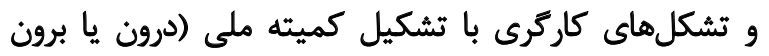

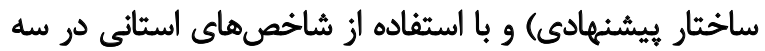

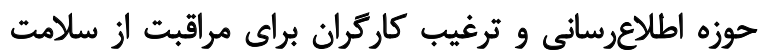

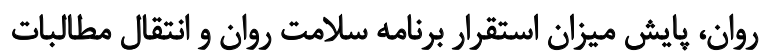
كاركران همكارى كنيند.

ث

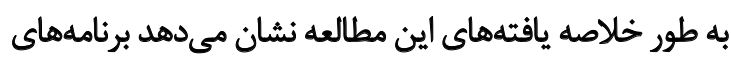

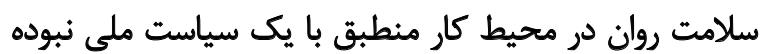

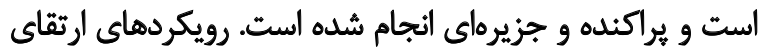

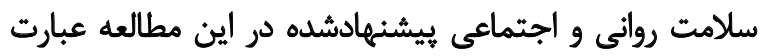
است از: مداخلات ترويجى (از جمله آموزش سبك زئن زندكى سالهم)، 
يس از مداخله براى بررسى خروجىهاى اوليه) بيان شدند [سب]. اين مطالعه ئروهشى براى سياست كذارى است و ديد كلان براى

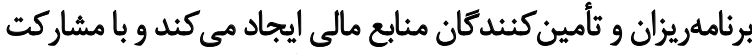

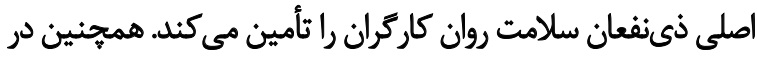

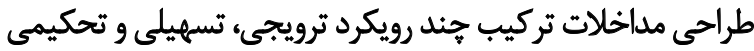

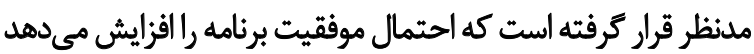

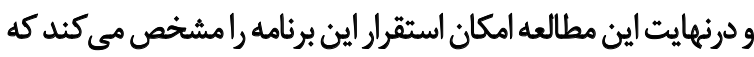
در بخش الزامات استقرار خلاصه شده است.

محدوديتهاي اين مطالعه دسترسىنداشتن به همه ذيىنفعان

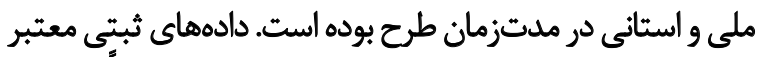

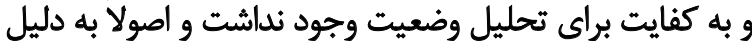

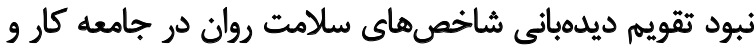

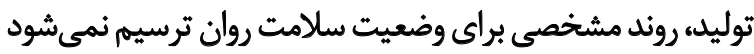

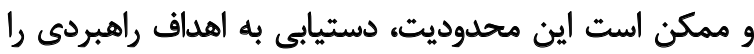

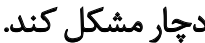

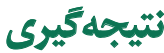

با توجه به نتايج بهدستآمده از اين مطالعه مئتوان

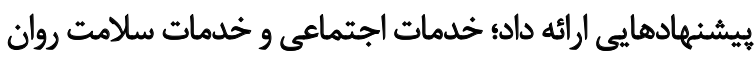

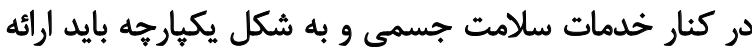

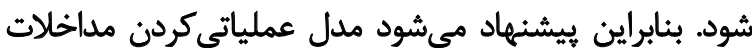

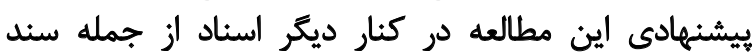

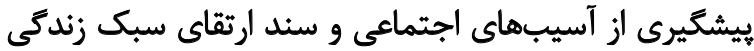

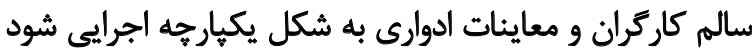

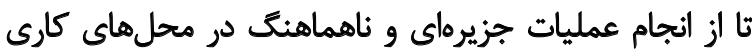

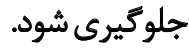

با توجه به تجربيات علم مديريت در اجراي سياستها و وائوان

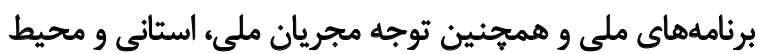

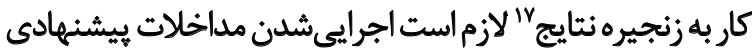

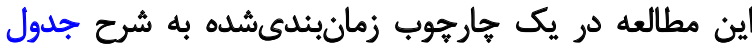

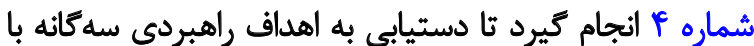

$$
\text { احتمال بيشترى ممكن شود. }
$$

مالاحظات اخلاقى

\section{يبيروى از اصول اخلاق يُوهش}

كليه اصول اخلاقي در اين مطالعه رعايت شده است.

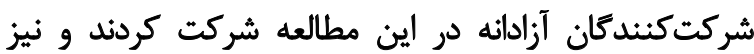

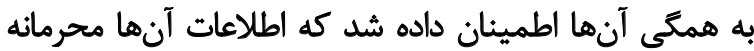

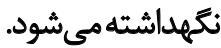

17. Result chain

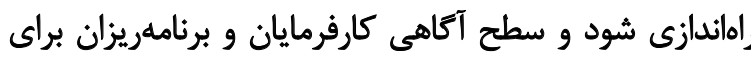

كاهش استرسهاى محيط كار افزايش يابد [ـهان].

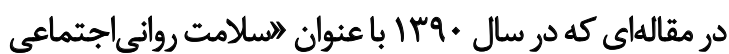

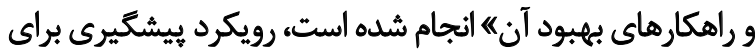

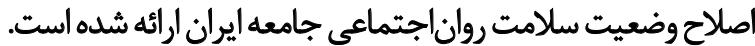

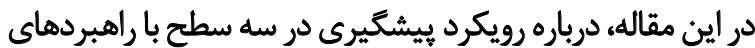

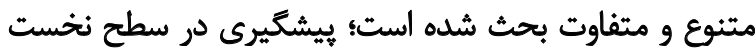

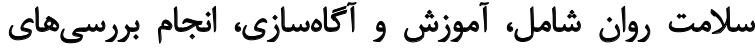

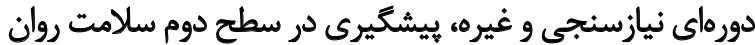

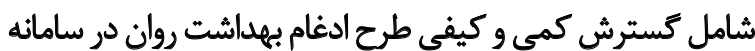

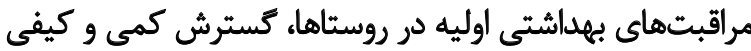

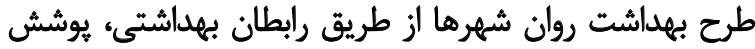

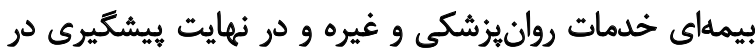

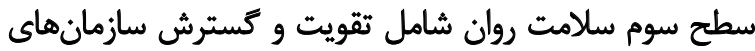

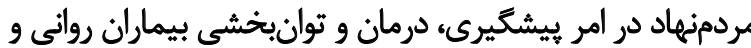

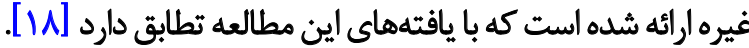

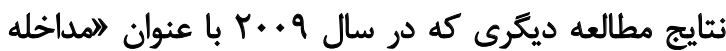
مشاركتى براي بهبود محيط كار درباره سلامت دران دوانى و و عملكرد

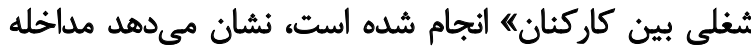

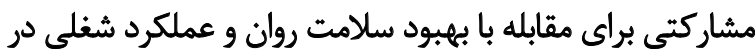

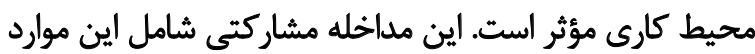

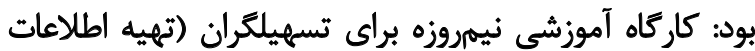

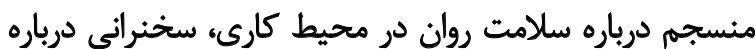

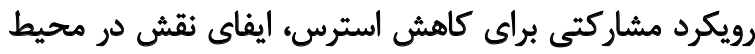

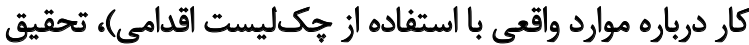

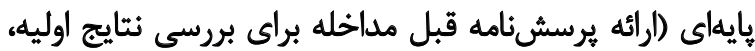

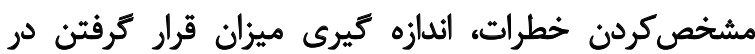

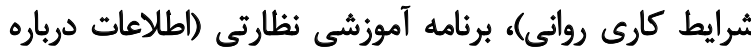

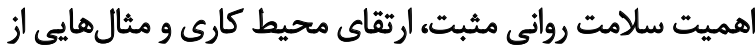

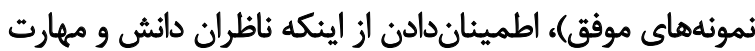

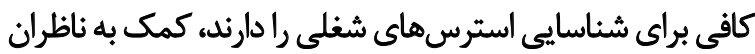

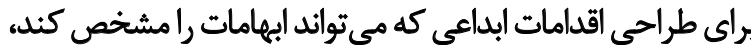

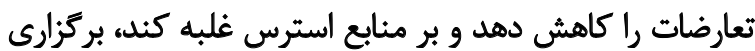

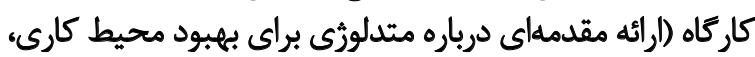

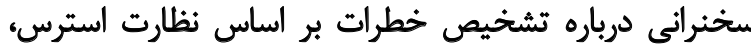

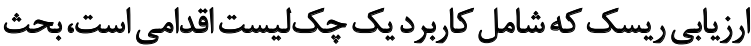

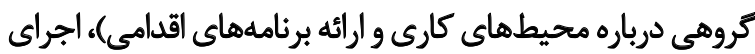

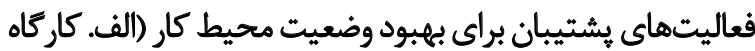

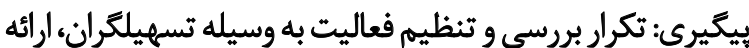

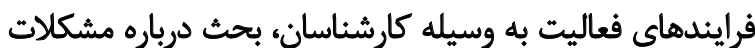

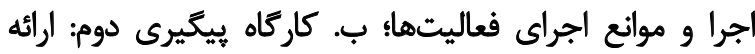

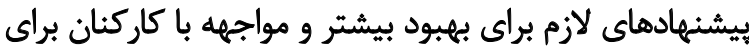

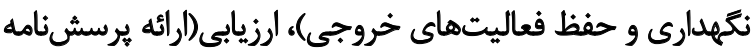




$$
\begin{aligned}
& \text { ماهى مالى } \\
& \text { اين مطالعه با يشتيبانى و حمايت مالى وزارت تعاون، كار و رفاه }
\end{aligned}
$$

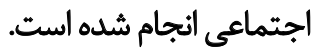

$$
\begin{aligned}
& \text { مشاركت نويسئد مكان }
\end{aligned}
$$

مفهومسازى: همه نويسندكان؛ روش: بهزاد دمارى؛ جستجو:

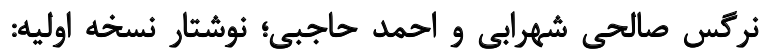

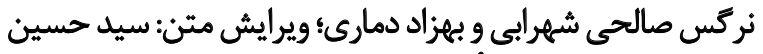

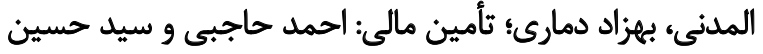

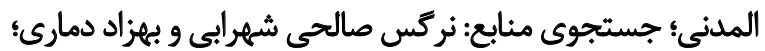

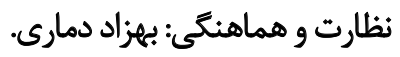

$$
\text { تعارض مئاقع }
$$

بنابر اظهار نويسندكان، مقاله هيجگُونه تعارض منافعى ندارد.

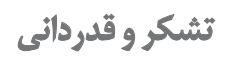

اين مطالعه به بيشنهادمركز توسعه بيشَّيرى سازمان بهزيستى

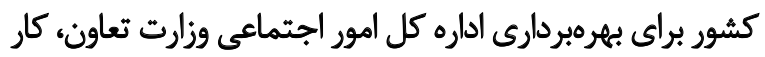

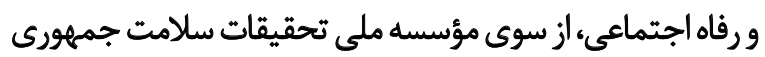

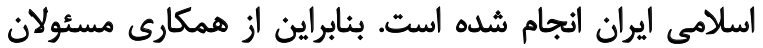

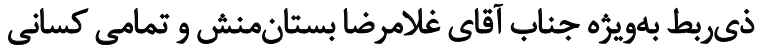

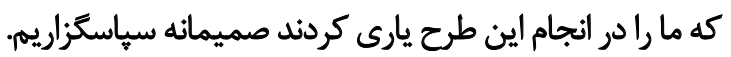




\section{References}

[1] Saberi Zafarghandi M. [Some of the challenges of mental health and addiction in Iran (Persian)]. Iranian Journal of Psychiatry \& Clinical Psychology. 2011; 17(2):157-61.

[2] World Health Organization. Mental health: New understanding, new hope. Geneva: World Health Organization; 2001.

[3] World Health Organization. World health report 2003: Shaping the future. Geneva: World Health Organization; 2003.

[4] Amin-Esmaeili M, Rahimi-Moaghar A, Sharifi V, Motevasselian SA, Hajebi A, Rad-Goodarzi R, et al. [The overall prevalence of psychiatric disorders in Iran: Results of National Survey of Mental Health and Wellbeing (2010-2011) (Persian)]. Paper presented at: The $30^{\text {th }}$ Annual Congress of Iranian Psychiatric Association. 22-25 October 2013; Tehran, Iran.

[5] Bagheriyazdi A, Bolhari J, Shahmohammad D. [An epidemiological study of psychological disorders on a rural area (Meibod, Yazd) in Iran (Persian)]. Iranian Journal of Psychiatry \& Clinical Psychology. 1994; 1(1):32-41.

[6] Bagheri Yazdi S A, Bolhari J, Peyravi H. [Mental health status of newly admitted students to Tehran University at 1994-1995 academic year (Persian)]. Iranian Journal of Psychiatry \& Clinical Psychology. 1995; 1(4):30-9.

[7] World Health Organization. World health report 2004: Changing history. Geneva: World Health Organization; 2004.

[8] Link BG, Phelan JC, Bresnahan M, Stueve A, Pescosolido BA. Public conceptions of mental illness: Labels, causes, dangerousness, and social distance. American Journal of Public Health. 1999; 89(9):1328-33. [DOI:10.2105/AJPH.89.9.1328] [PMID] [PMCID]

[9] Kaheh D, Heivadi T. [Job satisfaction \& mental health (Persian)]. Payesh. 201 2; 11(3):391-7.

[10] Vasiliadis HM, Lesage A, Adair C, Boyer R. Service use for mental health reasons: Cross-provincial differences in rates, determinants, and equity of access. The Canadian Journal of Psychiatry. 2005; 50(10):614-9. [DOI:10.1177/07 0674370505001007] [PMID]

[11] Gabriel P, Liimatainen MR, International Labour Office. Mental health in the workplace: Introduction, executive summaries. Geneva: International Labour Office; 2000.

[12] Nazari AM, Asadi M. [The effectiveness of cognitive group therapy on decreasing depression among high school students (Persian)]. Knowledge \& Health. 2011; 6(1):44-8

[13] World Health Organization. World health report 2008: Primary health care (Now More Than Ever). Geneva: World Health Organization; 2008

[14] World Health Organization. Integrating the response to disorders and other chronic diseases in health care system. Geneva: World Health Organization; 2014.

[15] Allen H. Is there a social worker in the house? Health care reform and the future of medical social work. Health \& Social Work. 2012; 37(3):183-6. [DOI:10.1093/hsw/hls021] [PMID]

[16] Robertson H. Integration of health and social care: A review of literature and models implication for Scotland. Scotland: Royal College of Nursing Scotland; 2011.
[17] Department of Health. Caring for people beyond tomorrow primary health and social care: A strategic framework for individuals, families and communities. London: Department of Health; 2015.

[18] Noorbala A. [Psychosocial Health and Strategies for improvement (Persian)]. Iranian Journal of Psychiatry \& Clinical Psychology. 2011; 17(2):151-6.

[19] Khalilzadeh R, Yavrian R, Khalkhali HR. [Investigating the relationship between job stress and depression and anxiety disorder in nurses of educational, medical hospitals of Urmia University of Medical Sciences (Persian)]. Journal of Urmia Nursing And Midwifery Faculty. 2005; 3(1):10-7.

[20] Malakooti K, Bakhshani N, Zohravi T. [Studying occupational stressors among hospital employees of Zahedan University of Medical Sciences (Persian)]. Iranian Journal of Psychiatry \& Clinical Psychology. 1994; 1(2-3):76-86

[21] Palahang H, Azimi K, Zarean J. [Epidemiology of mental disorders in factory workers in Shahr-e-Kord and Brojen (Persian)]. Iranian Journal of Psychiatry \& Clinical Psychology. 1999; 5(12):100-9

[22] Dadgar, M. [Validity and Reliability concepts of Questionnaire (Persian)]. Tehran: Noandishan Aria Kohan; 2017.

[23] Sharifi V, Asadi SM, Mohammadi M, Amini H, Kaviani $\mathrm{H}_{\text {, }}$ Semnani Y, et al. Reliability and feasibility of implementing the Persian version of Diagnostic of the Structured Diagnostic InterView for DSM-IV (SCID). Advances in Cognitive Psychology. Journal of New Cognitive Sciences. 2004; 6(1-2):10-22.

[24] Expediency Discernment Council. [Constitution of the Islamic Republic of Iran (Persian)]. Tehran: Expediency Discernment Council; 1979.

[25] Expediency Discernment Council. [The 20-year vision document of the Islamic Republic of Iran 1404 (Persian)]. Tehran: Islamic Republic of Iran; 2005 .

[26] The Office of the Supreme Leader. [A quantitive and qualitative development of health and medical insurance, providing justice and promoting health, especially in underdeveloped areas, and providing special assistance to needy group (Persian)] [Internet]. 2014 [Updated 2014 April 7]. Available from: www.leader.ir/fa/ content/11651/leader.ir

[27] Office of the Supreme Leader's Office. General Population Policy Announcement by the Supreme Leader of the Islamic Republic of Iran [Internet]. 2014 [Updated 20 May 2014]. Available from: https://en.irna.ir/news/2695875/Supreme-Leader-outlinesIran-s-general-population-policies.

[28] Office of the Supreme Leader's Office. [General policies of the administrative system Announcement by the Supreme Leader of the Islamic Republic of Iran (Persian)] [Internet]. 2014 [Cited 7 April 2014]. Available from: www.leader.ir/fa/content/11651/leader.ir

[29] Office of the Supreme Leader's Office. [General Counter Narcotics Policies Announcement by the Supreme Leader of the Islamic Republic of Iran (Persian)] [Internet]. 2014 [Cited 7 April 2014]. Available from: www.leader.ir/fa/content/11651/leader.ir

[30] The President's Office, Deputy of Strategic Planning and Control. [The text of the $5^{\text {th }}$ Development Plan Law of the Islamic Republic of Iran 2011-14 (Persian)]. Tehran: The President's Office, Deputy of Strategic Planning and Control; 2010. 
[31] National document of the prevention and control of non-communicable diseases. Geneva: World Health Organization; 2012.

[32] Ministry of Health. [The comprehensive mental health program of the country based on the map of the health system development of the Islamic Republic of Iran; 2011-15 (Persian)]. Tehran: Ministry of Health; 2010

[33] Yaghoobi H, Alaeddini F, Esmaeeli I, Almadani H, Bostanmanesh Gh, Sadeghi M. Mental Health Status and Quality of Work Life in Industrial and Manufacturing Centers: A Survey on the Role of Job Stressors. Tehran: Department of Cultural and Social Affairs of the Ministry of Labor SC-oaSWatWO; 2015.

[34] World Health Organization. Mental health atlas 2011. Geneva, World Health Organization; 2011.

[35] Hashemzadeh E, Aurangi M, Bahrehdar M. [The relationship between job stress and mental health in a group of hospital employees in Shiraz (Persian)]. Iranian Journal of Psychiatry and Clinical Psychology. 2000; 6(2-3):55-63. 